\title{
MR Imaging of Solitary Fibrous Tumors in the Head and Neck
}

Hyun Jeong Kim, MD

Ho Kyu Lee, MD²

Jeong Jin Seo, MD ${ }^{3}$

Hyung Jin Kim, MD

Ji Hoon Shin, MD²

Ae Kyung Jeong, $\mathrm{MD}^{5}$

Jeong Hyun Lee, MD²

Kyung Ja Cho, MD ${ }^{6}$

Index terms:

Magnetic resonance (MR)

Head and neck neoplasms

Head and neck neoplasms, MR

Korean J Radiol 2005; 6 : 136-142

Received November 17, 2004; accepted after revision July 7, 2005.

'Department of Radiology, Daejeon St. Mary's Hospital, College of Medicine, The Catholic University; ${ }^{2}$ Department of Radiology, Asan Medical Center, University of Ulsan College of Medicine; ${ }^{3}$ Department of Radiology, Chonnam National University Medical School; ${ }^{4}$ Department of Radiology, Samsung Medical Center, Sungkyunkwan University School of Medicine; ${ }^{5}$ Department of Radiology, Ulsan University Hospital, University of Ulsan College of Medicine; ${ }^{6}$ Department of Diagnostic Pathology, Asan Medical Center, University of Ulsan College of Medicine

Address reprint requests to: Ho Kyu Lee, MD, Department of Radiology, Asan Medical Center, University of Ulsan College of Medicine, 388-1 Poongnap-dong, Songpa-gu, Seoul 138-736, Korea.

Tel. (822) 3010-4400

Fax. (822) 476-4719

e-mail: rad_1970@yahoo.co.kr
Objective: Solitary fibrous tumor (SFT) is a very rare tumor. The purpose of this study is to determine the MR imaging features of SFT in the intracranial and extracranial head and neck regions.

Materials and Methods: We retrospectively reviewed six MR images and two CT images of six histologically proven cases of SFT that occurred in four men and two women, and their ages ranged from 46 to 59 years. These imaging findings were correlated with the microscopic findings of their surgical specimens.

Results: Six SFTs arose in the meninges (the petrous ridge and the pituitary fossa), the parotid gland, the parapharyngeal space, the buccal space and the maxillary sinus. On the MR images, SFTs in the intracranial and extracranial head and neck regions were mostly isointense to the muscle on the T1-weighted images, they were hyperintense on the T2-weighted images and they all had intense enhancement. On the T1- and T2-weighted images, hypointense lines were observed within in five SFTs. On the CT images, the SFTs were hypodense to the muscle on the unenhanced images and they were heterogeneously enhanced on the contrast-enhanced images. An exceptional case of pituitary SFT was hypointense on the T2-weighted images and it was hyperdense on the unenhanced CT images, which correlated with the increased collagenous component and the cellular compactness.

Conclusion: The imaging features of SFT are nonspecific; however, SFT should be included in the differential diagnosis of masses involving the intracranial and extracranial head and neck regions.

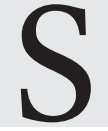

olitary fibrous tumor (SFT) is the current name for a distinctive neoplasm that most frequently occurs in the pleura. Since Klember and Rabin first described SFT as a localized fibrous mesothelioma in 1931 (1), the histogenesis of the solitary fibrous tumor has been debated as to whether it is a tumor of a mesothelial or mesenchymal cell origin, and the latter is now the favored answer $(2,3)$.

Although it is an uncommon tumor, SFT of the pleura is a well-established entity. More recently, attention has been drawn to the presence of the occasional SFTs that arise at extrapleural sites such as the lung, mediastinum, pericardium, peritoneum, meninges, head and neck (4-8, 11-13). Despite its characteristic histologic and immunohistochemical features, SFT of the head and neck remains a diagnostic challenge to both clinicians and radiologists, and it is often poorly recognized and confused with other neoplasms that more commonly occur at the head and neck. A review of the literature reveals sporadic reports on the imaging findings of SFT in the intracranial and extracranial head and neck regions, but really, there is only rather 
limited description of the imaging features of this tumor in the literature. During the past five years, we have encountered six cases of SFT in the intracranial and extracranial head and neck regions. In this study, we describe the CT and MR imaging features of these six cases of SFT.

\section{MATERIALS AND METHODS}

The clinical data and imaging studies of six patients who suffered with SFT involving the intracranial and extracranial head and neck regions were retrospectively reviewed. These patients were diagnosed during the five-year period from January 1998 to December 2002. The study includes four men and two women, and their mean age was 52 years (age range; $46-59$ years). All six patients underwent MR imaging and two patients underwent CT examinations. The MR imaging was performed using a 1.5-T MR unit (Signa; GE Medical Systems, Milwaukee, WI, USA) equipped with a head coil. An axial T1-weighted spin echo sequence (TR/TE/NEX, 466-516/11-14/2; field of view, $18-20 \mathrm{~cm}$; section thickness, $4-5 \mathrm{~mm}$ with a $1 \mathrm{~mm}$ gap; matrix size, $256 \times 256$ ) and an axial T2-weighted spin echo sequence (TR/TE/NEX, 4016 -4000/96-104/1; field of view, $18-20 \mathrm{~cm}$; section thickness, $4-5 \mathrm{~mm}$ with a $0.4-1$ mm gap; matrix size, $256 \times 256$ ) were obtained for the precontrast MRI. In addition, contrast-enhanced T1weighted spin echo images were obtained in the axial, sagittal and coronal planes after the intravenous injection of $0.1 \mathrm{mmol} / \mathrm{kg}$ of gadolinium dimeglumine. The $\mathrm{CT}$ scan was obtained using a spiral CT scanner (Hispeed; GE Medical System, Milwaukee, WI, USA). The scanning parameters were $120 \mathrm{kVp}, 200 \mathrm{~mA}$ and a 0.8 -sec scan time. Both the unenhanced and enhanced scans were obtained in two patients. One patient underwent only unenhanced CT scanning. The enhanced scans were obtained after the injection of $150 \mathrm{ml}$ of iopromide (Ultravist 300, Schering, Seoul, Korea); $100 \mathrm{ml}$ was injected as a bolus before scanning and $50 \mathrm{ml}$ was infused as a drip during scanning. Contiguous scans with $5-\mathrm{mm}$ collimation were obtained at $5-\mathrm{mm}$ intervals from the external auditory canal to the thoracic inlet for the head and neck imaging, and from the top of the head to the skull base for the brain imaging with the patient performing quiet respiration. The images were reviewed by two radiologists working in consensus, and they were only aware of the histologic diagnosis. Both the CT and MR images were evaluated for the location, margin, contour, MR signal intensity or CT density, internal architecture, pattern of enhancement and the change of the adjacent structure. On the CT and the T1- and T2-weighted MR images, the density and signal intensity abnormalities were categorized as low, iso- or high density/signal intensity as compared with the neck musculature. The margin was graded as well defined or ill-defined, and the contour was graded as smooth or irregular. The pattern of intratumoral enhancement was categorized as homogeneous or heterogeneous, and the degree of enhancement was categorized as strong, moderate or weak. These MR and CT findings were correlated with the microscopic findings of the surgically obtained specimens. Surgical excision was performed in all patients. The histologic evaluation and immunohistochemical studies were performed on the excised specimens. The diagnosis of SFT was established on the basis of the histopathologic appearance and the immunohistochemical

Table 1. Summary Clinical and Imaging Features in Six Patients

\begin{tabular}{|c|c|c|c|c|c|c|c|c|c|c|c|c|}
\hline \multirow[t]{2}{*}{ Case } & \multirow{2}{*}{$\begin{array}{l}\text { Age/ } \\
\text { Sex }\end{array}$} & \multirow[t]{2}{*}{ Symptom } & \multirow[t]{2}{*}{ Location } & \multirow{2}{*}{$\begin{array}{l}\text { Margin/ } \\
\text { Contour }\end{array}$} & \multirow{2}{*}{$\begin{array}{l}\text { Preoperation } \\
\text { Diagnosis }\end{array}$} & \multicolumn{3}{|c|}{ MR } & \multicolumn{3}{|c|}{ CT } & \multirow[b]{2}{*}{ Comment } \\
\hline & & & & & & $\mathrm{T} 1$ & T2 & $\begin{array}{l}\text { Pattern / } \\
\text { arrade of Er }\end{array}$ & Streak & Density & $\begin{array}{l}\text { Pattern/ } \\
\text { Arrade of En }\end{array}$ & \\
\hline 1 & $56 / F$ & headache & $\begin{array}{l}\text { meninges } \\
\text { (petrous ridge) }\end{array}$ & $\begin{array}{l}\text { well/ } \\
\text { smooth }\end{array}$ & meningioma & iso & high & $\begin{array}{l}\text { homo/ } \\
\text { strong }\end{array}$ & + & low & $\begin{array}{l}\text { hetero/ } \\
\text { strong }\end{array}$ & dural 'tail' \\
\hline 2 & $56 / \mathrm{M}$ & $\begin{array}{l}\text { visual } \\
\text { disturbance }\end{array}$ & $\begin{array}{l}\text { meninges } \\
\text { (pituitary fossa) }\end{array}$ & $\begin{array}{l}\text { well/ } \\
\text { smooth }\end{array}$ & $\begin{array}{l}\text { pituitary } \\
\text { adenoma }\end{array}$ & iso & low & $\begin{array}{l}\text { hetero/ } \\
\text { strong }\end{array}$ & - & high & ND & dural 'tail' \\
\hline 3 & $59 / \mathrm{M}$ & palpable mass & $\begin{array}{l}\text { deep lobe of } \\
\text { parotid gland }\end{array}$ & $\begin{array}{l}\text { well/ } \\
\text { irregular }\end{array}$ & $\begin{array}{l}\text { pleomorphic } \\
\text { adenoma }\end{array}$ & iso & high & $\begin{array}{l}\text { hetero/ } \\
\text { strong }\end{array}$ & + & & ND & $\begin{array}{c}\text { erosion } \\
\text { of mandible }\end{array}$ \\
\hline 4 & $49 / F$ & palpable mass & $\begin{array}{l}\text { parapharyngeal } \\
\text { space }\end{array}$ & $\begin{array}{l}\text { well/ } \\
\text { smooth }\end{array}$ & $\begin{array}{l}\text { neurogenic } \\
\text { tumor }\end{array}$ & iso & high & $\begin{array}{l}\text { homo/ } \\
\text { strong }\end{array}$ & + & & ND & $\begin{array}{l}\text { erosion } \\
\text { of palate }\end{array}$ \\
\hline 5 & $46 / \mathrm{M}$ & palpable mass & buccal space & $\begin{array}{l}\text { well/ } \\
\text { smooth }\end{array}$ & $\begin{array}{l}\text { pleomorphic } \\
\text { adenoma }\end{array}$ & iso & high & $\begin{array}{l}\text { homo/ } \\
\text { strong }\end{array}$ & + & & ND & \\
\hline 6 & $38 / \mathrm{M}$ & nasal bleeding & maxillary sinus & $\begin{array}{l}\text { well / } \\
\text { smooth }\end{array}$ & angiofibroma & iso & high & $\begin{array}{l}\text { homo/ } \\
\text { strong }\end{array}$ & + & & ND & $\begin{array}{c}\text { erosion } \\
\text { of sinus wall }\end{array}$ \\
\hline
\end{tabular}

Note. - En $=$ enhancement, hetero $=$ heterogeneously, homo $=$ homogeneously, ill $=$ ill-defined, irregular $=$ irregular-contoured, iso $=$ isointense, $\mathrm{ND}=$ not done, smooth = smooth-contoured, strong = strong-enhanced, weak = weak-enhanced, well = well-defined 
pattern of a diffuse and strong positive reaction for CD34. The diagnostic histopathologic findings were the presence of a haphazard growth pattern of short spindle cells having scant cytoplasm and a bland cytologic appearance, and these cells were separated by strands of rope-like collagen $(5-8)$.

\section{RESULTS}

The clinical and imaging features of our six patients are given in Table 1. There were two intracranial SFTs and four extracranial SFTs included in this study. The individual locations were the meninges, including the petrous ridge and the pituitary fossa, the parotid gland, the parapharyngeal space, the buccal space and the maxillary sinus. The presenting symptoms were headache in a case of the meninges location, visual disturbance in a case of the pituitary fossa location and an indolent palpable mass in the extracranial located cases. Preoperative diagnosis was meningioma for a case of the petrous ridge location, pituitary adenoma for a case of the pituitary fossa location, pleomorphic adenoma for the cases of the parotid gland and buccal space locations, and neurogenic tumor for the cases with parapharyngeal space and paraspinal area locations. Of the six SFTs, five were well-defined and smooth-contoured, except for one that had an irregular contour. On the MR images, all the SFTs were observed as having iso-signal intensity on the T1-weighted images (Figs. 1D and 3A) and they had high signal intensity on the T2-weighted images (Figs. 1C and 3B), except for a case having a pituitary fossa location, and this tumor had a low signal intensity on the T2-weighted images (Fig. 2B). On the contrast-enhanced T1-weighted images, homogeneous enhancement was observed in four SFTs (Figs. 1E and 3C)

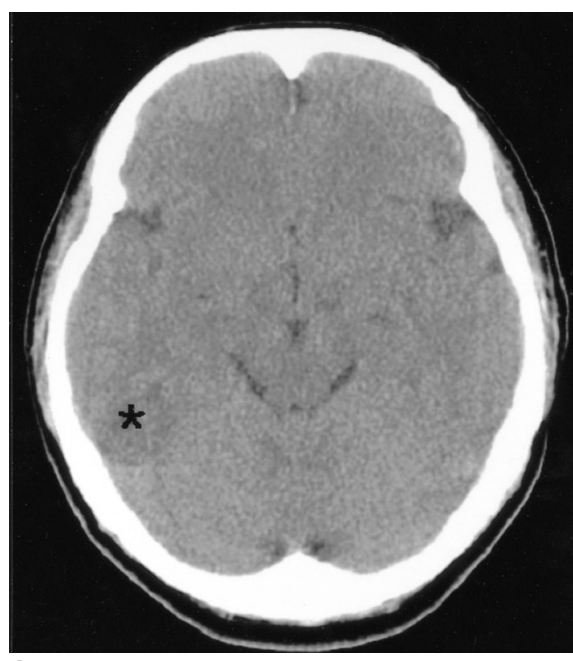

A

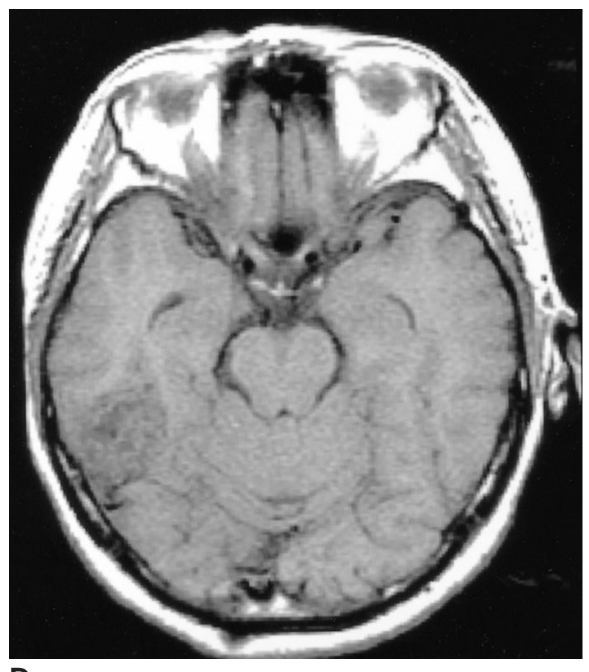

D

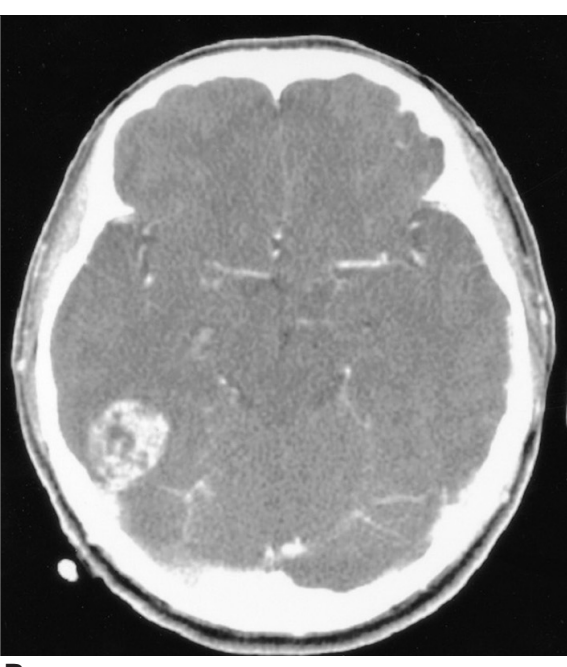

B

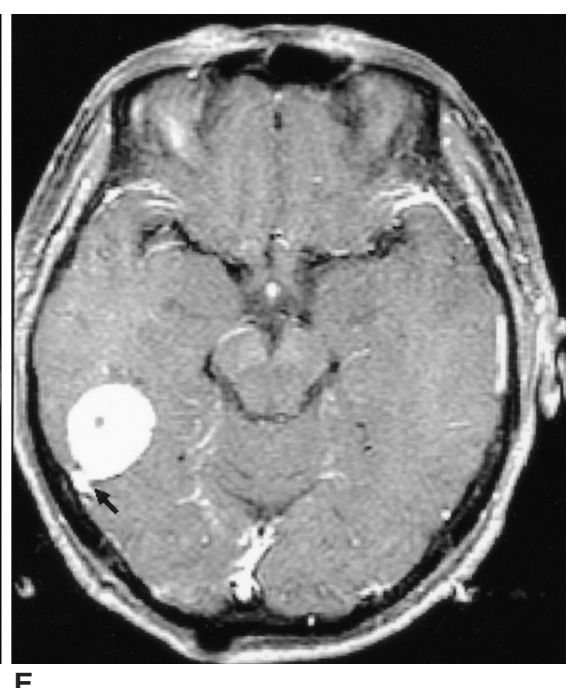

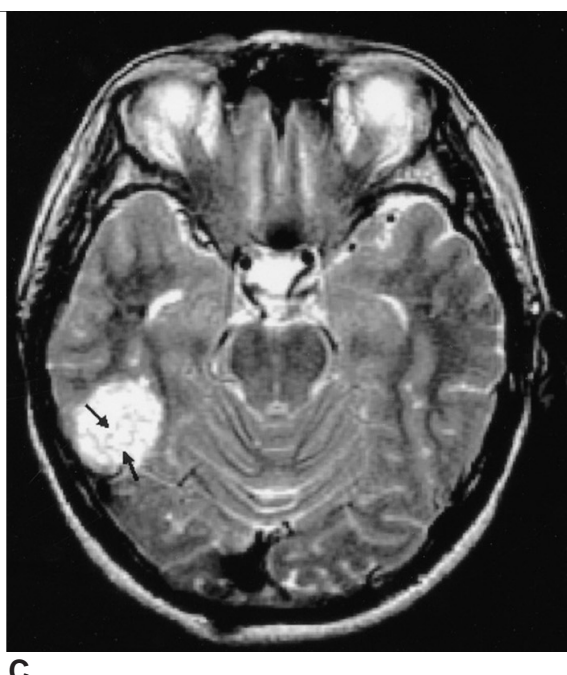

C

Fig. 1. Images of a 56-year-old man presenting with headache (case 1).

A. The axial unenhanced CT image shows an ill-defined low density lesion abutting the temporal lobe $\left(^{*}\right)$.

B. The axial contrast-enhanced CT image demonstrates the lesion to be a well-defined, heterogeneously well-enhanced, rounded and contoured mass.

C. The axial T2-weighted MR image (4000/96 [TR/TE]) shows the lesion to be a well-defined, round mass that is heterogeneously hyperintense to the muscle and there are multiple, hypointense streaks (arrows) within the mass.

D. The axial T1-weighted MR image (500/11) shows an isointense mass. The hypointense streaks on the T2-weighted image are also hypointense.

E. The axial contrast-enhanced T1-weighted MR images (500/11) reveal homogeneous enhancement of the mass that is based on the petrous ridge and it has a dural 'tail' (arrow). The streaks are well enhanced, as same as the other portions of the mass. 


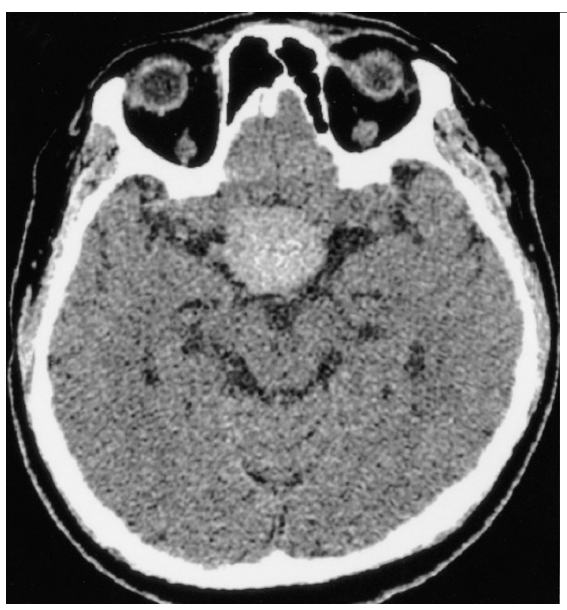

A

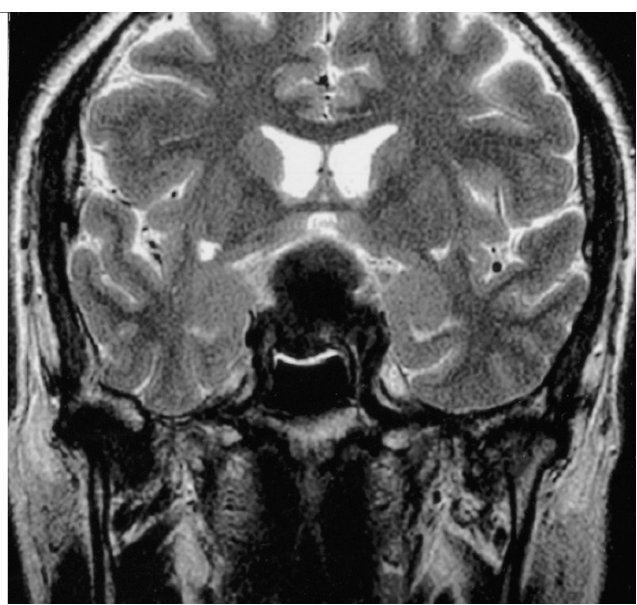

B

Fig. 2. Images of a 56-year-old man presenting with visual disturbance (case 2).

A. The axial unenhanced CT image shows the lesion to be well-defined and hyperdense.

B. The T2-weighted axial MR image (4000/98 [TR/TE]) shows a well-defined 'figure eight' shaped mass that is hypointense to the muscle in the pituitary fossa and it has a suprasellar extension.

C. Photomicrograph shows the prominent collagenous tissue with cellular areas that are composed of haphazardly arranged spindle cells. (hematoxylin-eosin stain, original magnification (100))

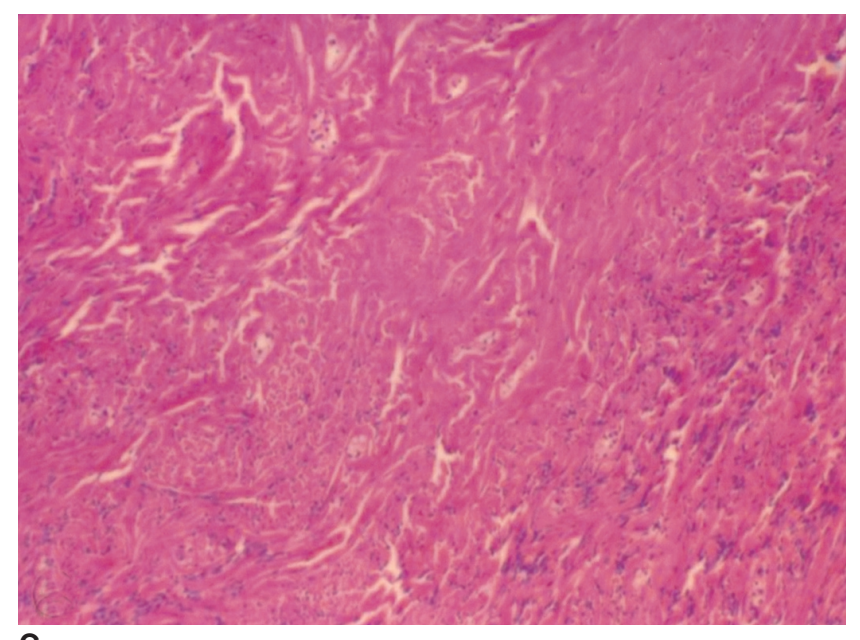

C

and heterogeneous enhancement was observed in two. All six SFTs were strongly enhanced. On the T1- and T2weighted images, linear or curvilinear low-signal-intensity lines were observed within five tumors, except a case having a pituitary fossa location (Figs. 1C, 1D, 3A, 3B and 4A). These hypointese lines were less enhanced than the other portions of the tumor in four cases (Fig. 3C), and these hypointense lines were enhanced to the same degree as the other portions of the tumor in one case (Fig. 1E).

On the unenhanced CT images, the tumors were observed as having low density in the case of the petrous ridge location (Fig. 1A) and the tumors had a high density in a case of the pituitary fossa location (Fig. 2A). On the contrast-enhanced CT images, heterogeneously strong enhancement was observed in a case having a petrous ridge location (Fig. 1B). Two tumors in the meninges showed adjacent meningeal thickening (a dural 'tail') (Fig. 1E). Adjacent bony erosion was seen in the SFTs having parotid gland and the parapharyngeal space locations due to the large size of the tumors. A SFT of the maxillary sinus expanded into the adjacent nasal cavity and then it was clinically misdiagnosed as angiofibroma. In a case of the tumor with the pituitary fossa location, the tumor displaced the pituitary gland upward.

Microscopic examination revealed benign SFT for all six patients. A more abundant collagenous component and relative hypocellularity were shown in the pituitary SFT of a low signal intensity on the T2-weighted images than was shown for SFTs of a high signal intensity on the T2weighted images (Figs. 2C and Fig. 3D). The hypocellular, but more collagenous areas in a tumor corresponded to the hypointense lines on the T1- and T2-weighted images.

All patients made uneventful recoveries and they are still clinically and radiologically free from tumor recurrence during the follow-up period that ranged from seven to 27 months (average follow-up period; 13 months).

\section{DISCUSSION}

Solitary fibrous tumor is an uncommon spindle cell tumor that usually occurs in the pleura. The presence of this tumor has also been recently reported in a number of extrapleural sites, including the intracranial and extracranial head and neck regions such as the meninges, orbit, nasal cavity, paranasal sinus, soft palate, epiglottis, thyroid, salivary gland, infratemporal fossa, buccal space and parapharyngeal space $(4-8,11-13)$. In our study, six SFTs were located, respectively, in the meninges (the petrous ridge and the pituitary fossa), parotid gland, parapharyngeal space, buccal space and the maxillary sinus. The primary SFT of the pituitary fossa in our study is the first one to be reported at this site.

Solitary fibrous tumors occur with equal frequency in both sexes and they usually occur in adults who are aged from 30 to 64 years (6). In our study, the age range was 
Kim et al.

also $46-59$ years, but the incidence was higher in men than in women with a sex ratio of 4:2. Clinically, the extrapleural lesions may present with symptoms related to the tumor site or with systemic symptoms such as hypoglycemia, arthralgia, osteoarthropathy or clubbing. These symptoms usually resolve with the tumors' removal $(4,6)$. Two of our study patients with intracranial SFTs presented with visual disturbance or headache due to the mass effects, and three patients with extracranial SFTs presented with a palpable mass (Table 1). One patient with a maxillary sinus SFT presented with nasal bleeding. None of our study patients experienced systemic symptoms.

Microscopically, the SFTs are well-circumscribed tumors; they are known to have a characteristic patternless arrangement consisting of a varying number of spindle cells randomly arranged in a collagenous background of variable vascularity. Characteristically, there are alternating hypercelluar and sclerotic hypocellular regions. Some cases have a hemangiopericytoma-like pattern of irregular branching vessels and occasionally a storiform or herringbone pattern is seen $(5-8,12,13)$. The SFT diagnosis is supported by a characteristic immunohistochemical profile.

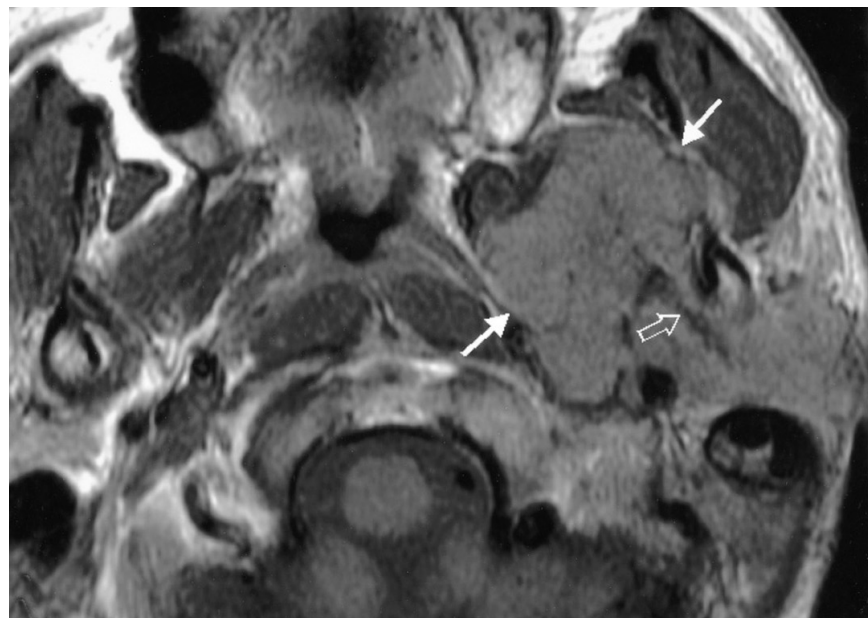

A

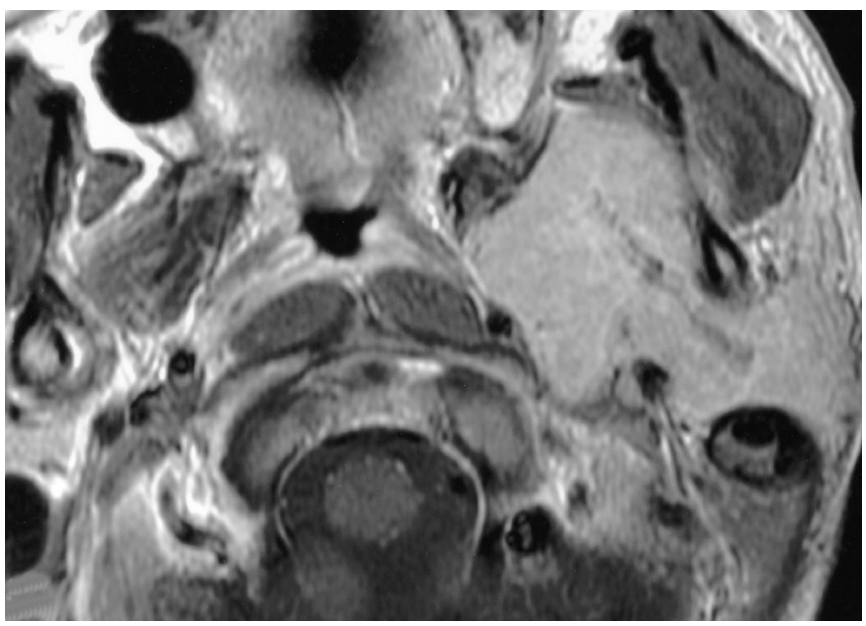

C

Fig. 3. Images of a 59-year-old man presenting with a painless left periauricular mass (case 3).

A. The T1-weighted axial MR image shows a well-defined, dumbbell-shaped mass (arrows) that is isointense to the muscle in both the left parapharyngeal space and the parotid space with widening of the stylomandibular tunnel. The mass medially displaces the parapharyngeal fat and the carotid sheath. Multiple hypointense streaks are seen in the mass (open arrow).

B. The T2-weighted axial MR image shows the heterogeneous high signal intensity of the mass (arrows). The streaks are also demonstrated as low signal intensity (open arrow).

C. The contrast-enhanced T1-weighted axial MR image reveals the homogeneously strong enhancement of the mass. The streaks were less enhanced than in the other portion of the tumor.

D. Photomicrograph shows that the tumor is composed of a haphazard proliferation of spindle cells separated from the hyalinized collagen tissue (hematoxylin-eosin, magnification x 200). The inlet shows that the tumor cells and the capillary endothelial cells have immunohistochemically positive CD34 results; this finding is consistent with that of solitary fibrous tumor (original magnification $\times 200$ ). 


\section{MR Imaging of Solitary Fibrous Tumors in Head and Neck}

SFTs strongly stain for CD34 and the intermediate filament vimentin, but they are usually negative for epithelial, vascular, neural crest and muscle markers $(5-8,13)$.

According to the reported MR features of SFTs, the signal intensity was isointense to muscle on the T1weighted images, the signal intensity increased with intravenous gadolinium and it was variable on the T2weighted images. It's been suggested that this variable signal intensity depends mainly on the differences in the main components of the tumor, namely, the amount of collagen and fibroblasts, and also on the presence of degeneration. Intense enhancement of an SFT is generally due to its high vascularity $(8,15)$. Several MR studies that were done on fibrosis reported that mature fibrous tissue usually has a low signal intensity on the T1-weighted, proton-density-weighted and T2-weighted images, and this is related to the areas of hypocellularity and the abundant collagen stroma $(9,10)$. In our study, the tumor signal intensity on the T2-weighted images decreased as the collagenous component increased (Figs. 2B, 2C, 3B and 3D). We also observed an interesting finding, that is, the linear or curvilinear hypointense lines within the tumors on the MR images in four cases (Figs. 1C, 1D and 3A). Those lines corresponded to the hypocellular collagenous stroma intervening in the hypercelluar area, and this hypocellular collagenous stroma was composed of a haphazard proliferation of spindle cells. Even if these hypointense lines were not specific for SFT, we suggest that these hypointense lines are helpful for including this rare tumor in the differential diagnosis of masses involving the intracranial and extracranial head and neck regions.

For the CT-pathologic correlation of nine cases having a pleural origin, Lee et al. (14) described these tumors as having isoattenuation relative to the adjacent musculature, and they had intense enhancement following intravenous contrast injection. The intratumoral low attenuation areas correlated with myxoid or cystic degeneration. In our study, an SFT located in the pituitary fossa was hyperdense on the unenhanced CT images. We presume that the compactly arranged, abundant, collagenous component of this tumor increased the density of the tumor on the CT images, and this was seen as a decreased signal on the T2weighted MR images.

Most intracranial SFTs have a dural origin, and although there have been several reports of intracranial and spinal meningeal SFTs $(8,11)$, an SFT in the pituitary region has never been reported on before. Thickened dural 'tails', hyperostosis, skull erosion and capping cysts may all be seen in meningeal SFTs (8). The two meningeal SFTs in our study were also shown to have dural tails.

The radiologic appearance for SFTs of the intracranial and extracranial head and neck regions is nonspecific, and this tumor is often misdiagnosed as being another type of common tumor on the initial images. In our case of the pituitary SFT, the tumor was initially considered to be a pituitary adenoma with hemorrhage because of its low signal intensity on the T2-weighted images. A transsphenoidal approach for resection of this tumor resulted in its incomplete excision because of the harder consistency of the SFT. This patient had to undergo repeated surgery using a transcranial approach in order to achieve complete tumor resection. Therefore, any suggestion of the characteristics of this hard, fibrous tumor, according to its MR signal intensity, may be important for the subsequent patient care.

Most SFTs, especially those in the extrapleural sites, are benign and they are cured with complete surgical excision. Previous reports have indicated that $13-37 \%$ of SFTs have been associated with local recurrence or histologic malignancy such as an invasive growth pattern, cellular pleomorphism, abundant mitotic activity or metastasis (5$8,10,16)$. There is no report that a benign SFT has a potential to transform into a malignant SFT.

\section{CONCLUSION}

Solitary fibrous tumor is an uncommon tumor occurring in the intracranial and extracranial head and neck regions. On the MR images, this tumor is seen as a well-defined, smooth or irregular, contoured mass. It is isointense relative to muscle on the T1-weighted images; the intensity increasing with intravenous gadolinium, and the intensity is variable on the T2-weighted images. Darker signal intensity on the T2-weighted images represents a firmer fibrous tumor composed of abundant collageneous stroma. Solitary fibrous tumor should be included in the differential diagnosis of masses involving the intracranial and extracranial head and neck regions because it has imaging findings similar to those of the other more common lesions such as schwannoma and meningioma.

\section{References}

1. Klemperer P, Rabin CB. Primary neoplasms of the pleura: a report of five cases. Arch Pathol 1931;11:385-412

2. England DM, Hochholzer L, McCarthy MJ. Localized benign and malignant tumors of the pleura. A clinicopathologic review of 223 cases. Am J Surg Pathol 1989;13:640-658

3. Dervan PA, Tobin B, O'Connor M. Solitary (localized) fibrous mesothelioma: evidence against mesothelial cell origin. Histopathology 1986;10:867-875

4. Goodlad JR, Fletcher CD. Solitary fibrous tumor arising at unusual sites: analysis of a series. Histopathology 1991;19:515522

5. Shin JH, Sung IY, Suh JH, Yang SO, Jeong YK, Lee JH, et al. 
Kim et al.

Solitary fibrous tumor in the buccal space: MR Findings with pathologic correlation. AJNR Am J Neuroradiol 2001;22:18901892

6. Jeong AK, Lee HK, Kim SY, Cho KJ. Solitary fibrous tumor of the parapharyngeal space: MR imaging findings. AJNR Am J Neuroradiol 2002;23:473-475

7. Kim TA, Brunberg JA, Pearson JP, Ross DA. Solitary fibrous tumor of the paranasal sinuses: CT and MR appearance. AJNR Am J Neuroradiol 1996;17:1767-1772

8. Martin AJ, Fisher C, Igbaseimokumo U, Jarosz JM, Dean AF. Solitary fibrous tumor of the meninges: case series and literature review. J Neurooncol 2001;54:57-69

9. Ferretti GR, Chiles C, Cox JE, Choplin RH, Coulomb M. Localized benign fibrous tumors of the pleura: MR appearance. J Comput Assist Tomogr 1997;21:115-120

10. Kransdorf MJ, Jelinek JS, Moser RP Jr, Utz JA, Hudson TM, Neal J, et al. Magnetic resonance appearance of fibromatosis. A report of 14 cases and review of the literature. Skeletal Radiol 1990;19:495-9
11. Pizzolitto S, Falconieri G, DeMaglio G. Solitary fibrous tumor of the spinal cord: a clinicopathologic study of two cases. Annals of Diagnostic Pathology 2004;8:268-275

12. Kessler A, Lapinsky J, Berenholz L, Sarfaty S, Segal A. Solitary fibrous tumor of the nasal cavity. Otolaryngol Head Neck Surg 1999;121;826-888

13. Sato J, Asakura K, Yokoyama Y, Satoh M. Solitary fibrous tumor of the parotid gland extending to the parapharyngeal space. Eur Arch Otorhinolaryngol 1998;255:18-21

14. Lee KS, Im J-G, Choe KO, Kim CJ, Lee BH. CT findings in benign fibrous mesothelioma of the pleura: pathologic correlation in nine patients. AJR Am J Roentgenol 1992;158:983-986

15. Tateishi U, Nishihara H, Morikawa T, Miyasaka K. Solitary fibrous tumor of the pleura: MR appearance and enhancement pattern. J Comput Assist Tomogr 2002;26:174-179

16. Sung SH, Chang JW, Kim JG, Lee KS, Han JH, Park SI. Solitary fibrous tumors of the pleura: surgical outcome and clinical course. Ann Thorac Surg 2005;79:303-7 